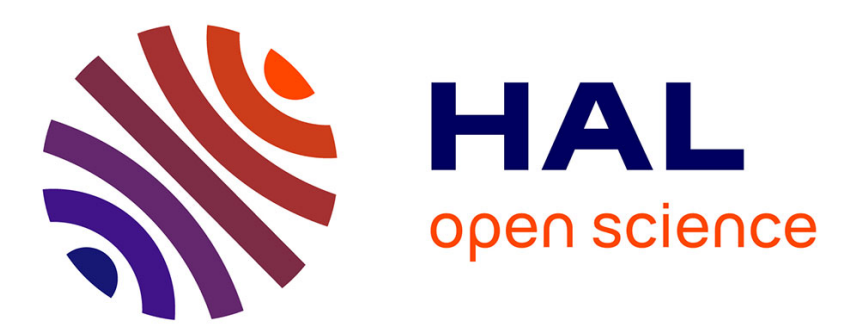

\title{
Leitbilder und Legitimierung herrscherlicher Macht im mittelalterlichen Zentralindien (8. bis 13. Jahrhundert)
}

Annette Schmiedchen

\section{To cite this version:}

Annette Schmiedchen. Leitbilder und Legitimierung herrscherlicher Macht im mittelalterlichen Zentralindien (8. bis 13. Jahrhundert). Die Macht des Herrschers, 4, V\&R unipress, pp.277-298, 2019, Macht und Herrschaft, 978-3-8471-1074-3. 10.14220/9783737010740.277 . hal-03012270

\author{
HAL Id: hal-03012270 \\ https://hal.science/hal-03012270
}

Submitted on 3 Dec 2020

HAL is a multi-disciplinary open access archive for the deposit and dissemination of scientific research documents, whether they are published or not. The documents may come from teaching and research institutions in France or abroad, or from public or private research centers.
L'archive ouverte pluridisciplinaire HAL, est destinée au dépôt et à la diffusion de documents scientifiques de niveau recherche, publiés ou non, émanant des établissements d'enseignement et de recherche français ou étrangers, des laboratoires publics ou privés. 


\section{Mechthild Albert/Elke Brüggen/Konrad Klaus (Hg.)}

\section{Die Macht des Herrschers}

Personale und transpersonale Aspekte

\section{Bonn University Press}

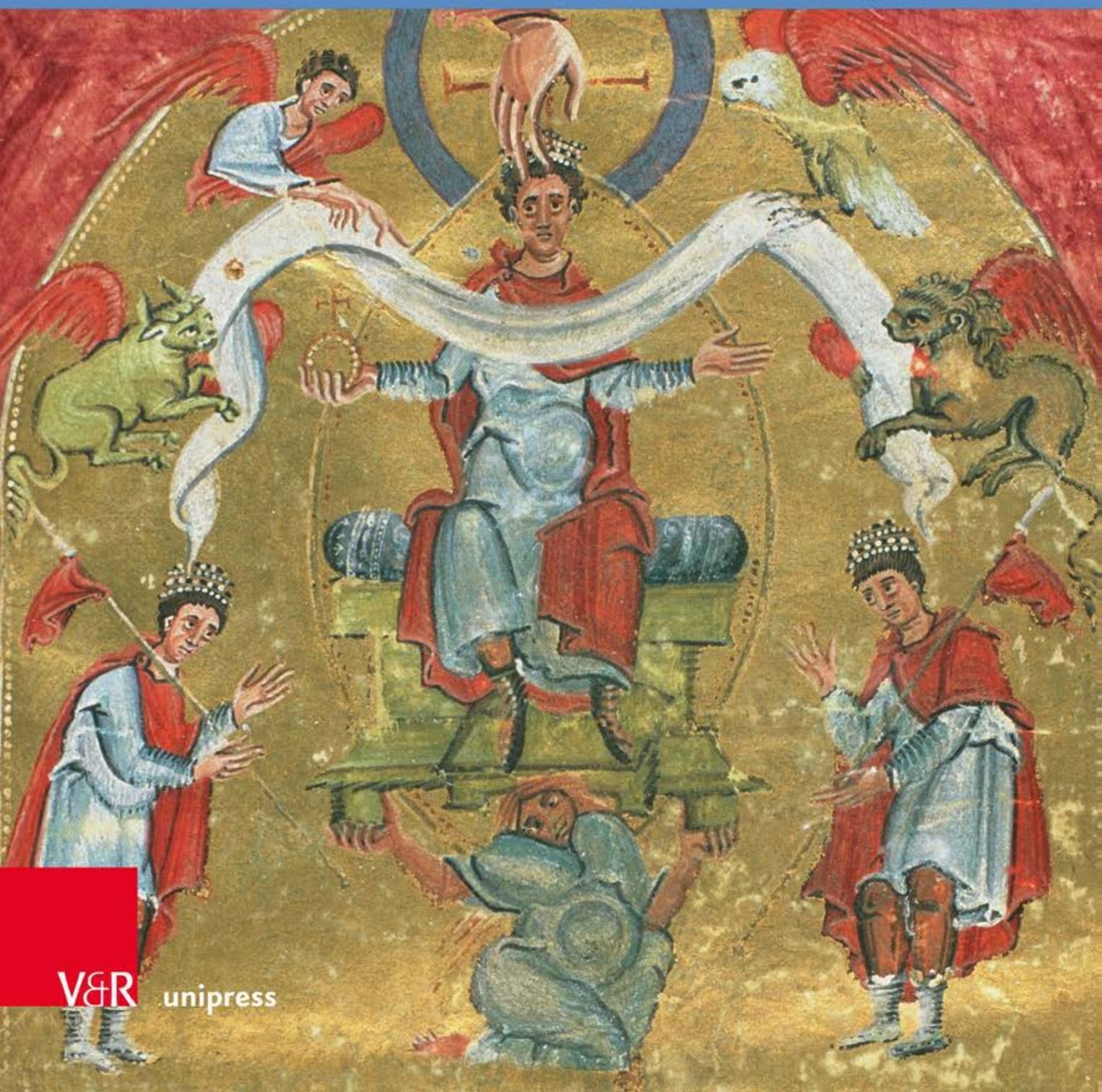




\section{Macht und Herrschaft}

Schriftenreihe des SFB 1167

„Macht und Herrschaft - Vormoderne Konfigurationen in transkultureller Perspektive“

Band 4

Herausgegeben von

Matthias Becher, Elke Brüggen und Stephan Conermann 


\title{
Mechthild Albert / Elke Brüggen / Konrad Klaus (Hg.)
}

\section{Die Macht des Herrschers}

\author{
Personale und transpersonale Aspekte
}

Mit 24 Abbildungen

V\&R unipress

Bonn University Press 


\section{UNIVERSITÄT BONN

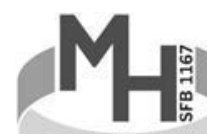

DFG

Bibliografische Information der Deutschen Nationalbibliothek

Die Deutsche Nationalbibliothek verzeichnet diese Publikation in der Deutschen

Nationalbibliografie; detaillierte bibliografische Daten sind im Internet über

https://dnb.d-nb.de abrufbar.

Veröffentlichungen der Bonn University Press

erscheinen im Verlag V\&R unipress GmbH.

Gedruckt mit freundlicher Unterstützung der Deutschen Forschungsgemeinschaft.

(C) 2019, V\&R unipress GmbH, Robert-Bosch-Breite 6, D-37079 Göttingen

Alle Rechte vorbehalten. Das Werk und seine Teile sind urheberrechtlich geschützt.

Jede Verwertung in anderen als den gesetzlich zugelassenen Fällen bedarf der vorherigen schriftlichen Einwilligung des Verlages.

Umschlagabbildung: Ottonisches Evangeliar, Widmungsblatt, fol. 16r @ Domkapitel Aachen; Foto: Pit Siebigs.

Vandenhoeck \& Ruprecht Verlage | www.vandenhoeck-ruprecht-verlage.com

ISSN 2511-0004

ISBN 978-3-8470-1074-6 


\section{Inhalt}

Vorwort zur Schriftenreihe ................. 7

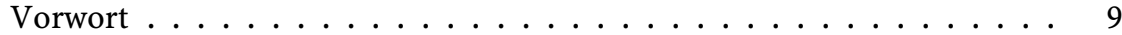

Matthias Becher

Die Macht des Herrschers zwischen Personalität und Transpersonalität.

Gedanken zur Einführung . . . . . . . . . . . . . . . . . . 19

Karl-Siegbert Rehberg

Herrscher als Typusfiguren der Verkörperung institutioneller Macht im

Kampffeld von Spannungsbalancen _. . . . . . . . . . . . 27

Stefan Esders

Regem iura faciunt, non persona. Der westgotische Treueid im Kräftefeld personaler und transpersonaler Konzepte der Legitimität politischer Herrschaft ....................... 69

Stacy S. Klein

Royal Women and Composite Sovereignty in Asser's 'Life of King Alfred' 155

Shigekazu Kondo

The Personal and Transpersonal Elements of the Governments of Thirteenth-Century Japan . . . . . . . . . . . . . . . . . 183

Martin Clauss

Überlegungen zur militärischen Macht eines mittelalterlichen Herrschers am Beispiel Eduards III. von England . . . . . . . . . . . . . . . . 191 
Cornelia Soldat

Primogenitur und Konsensherrschaft unter Vasilij III. und Ivan IV. in

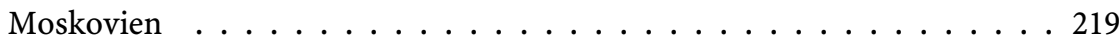

John Baines

Ruler, Court, and Power: The King and Institutions in Early Egypt . . . . 239

Annette Schmiedchen

Leitbilder und Legitimierung herrscherlicher Macht im mittelalterlichen

Zentralindien (8. bis 13. Jahrhundert) _ . . . . . . . . . . . 277

Seraina Plotke

Narrative Negotiations of Sovereign Power in 'King Rother' . . . . . . . . 299

Beate Kellner

Herrscherpreis und Herrscherkritik. König Philipp in Sangsprüchen

Walthers von der Vogelweide . . . . . . . . . . . . . . . 313

Kai Nonnenmacher

Auftrag und Kritik: trobadoreske Politik des Sirventes . . . . . . . . . . 351

Liste der Autorinnen und Autoren . . . . . . . . . . . . . . . . 369 


\title{
Leitbilder und Legitimierung herrscherlicher Macht im mittelalterlichen Zentralindien (8. bis 13. Jahrhundert)
}

\begin{abstract}
Royal epigraphs recording religious endowments of villages and/or land constitute the main sources for questions related to rule and power in premodern (or rather, pre-Islamic) South Asia. Most of the medieval title deeds were written in Sanskrit and engraved on copper plates. Beside the details of a specific endowment, these copper-plate charters contain the titles of the royal donors and their immediate predecessor(s), as well as the panegyric genealogies of their dynasties. The latter reveal a great deal of information about various aspects of the legitimation of Indian kings and about concepts of a 'good' ruler. One of the criteria for 'good' rule is also manifested in the main objective of copper-plate charters: (the recording of) royal grants in favour of religious donees.

On the basis of epigraphic material from central India issued by the Rāstrakūta dynasty (eighth to tenth centuries), as well as by the Silähära and Yädava dynasties (tenth to thirteenth centuries), this article explores the mechanisms of the self-representation of the rulers in their charters. It attempts to show that the genealogical and panegyric descriptions played a very important role in legitimation policies. Each of the dynasties mentioned above used several different versions of the metrical descriptions of their pedigrees in order to explain their claim to the throne in disputes, thus strengthening their own legitimation and weakening that of their rivals.

Furthermore, the copper-plate charters also provide an insight into several aspects of the stabilization policies pursued by the rulers: refined structures of vassalage, systematic matrimonial alliances, and the almost comprehensive settlement of Brahmins in all regions of the kingdoms, which led to their large-scale migration within the subcontinent. Brahmins were preferred recipients of endowments of land as they acted as a supraregional foundation for the legitimation of the rulers; and it was also Brahmins who drafted the dynastic genealogies at the royal courts.
\end{abstract}

Die Region Zentralindien umfasst vor allem das Hochland des Dekkhan. Im Folgenden wird diese Bezeichnung auf ein Kernterritorium bezogen, das dem heutigen indischen Bundesstaat Maharashtra entspricht, aber auch angrenzende Gebiete im Süden und Westen einschließt, die in Karnataka bzw. Gujarat liegen. In der Periode vom 8. bis 13. Jahrhundert regierten dort die Dynastien der 
Rāșțrakūṭas (8.-10. Jahrhundert), der Śilāhāras und der Yādavas (10.-13. Jahrhundert). ${ }^{1} \mathrm{Da}$ - mit Ausnahme der srilankischen und kaschmirischen Chroniken - für die meisten Regionen des vormodernen (bzw. vorislamischen) Südasiens keine historiographische Literatur im engeren Sinne vorliegt, ${ }^{2}$ stellen Inschriften die wichtigsten Quellen für eine Rekonstruktion dieser Perioden der Geschichte dar. Dabei bilden auf Kupfertafeln eingravierte und überwiegend in Sanskrit verfasste königliche Landstiftungsurkunden ${ }^{3}$ auf dem südasiatischen Festland die wichtigste epigraphische Gattung. Kupfertafelinschriften enthalten neben Details zu religiösen Stiftungen auch Titulaturen der Könige sowie dynastische Genealogien und herrscherliche Eulogien. ${ }^{4}$ Die Genealogien bieten umfassende Informationen zur Verquickung vom Leitbild eines ,guten' Herrschers mit der konkreten Legitimierung von herrscherlicher Macht.

Zunächst sollen die Selbstrepräsentation der Könige der Rāṣțrakūta-Dynastie und die spätere innerdynastische Rezeption früherer Regenten dieses Herrscherhauses im Mittelpunkt stehen. Aus den insgesamt 75 erhaltenen Urkunden ${ }^{5}$ geht hervor, dass sowohl die Titulaturen als auch die genealogischen und eulogischen Darstellungen eine sehr wichtige Funktion im Rahmen der Legitimation der einzelnen Herrscher hatten. In den Schilderungen wird deutlich, welche Vorstellungen über die Berechtigung eines Thronfolgeanspruchs verbreitet waren und wie sich diese im Laufe der Zeit wandelten. Diese legitimatorischen Fragen wiederum waren sehr eng mit der offiziellen Förderung religiöser Institutionen und Personen im Rahmen einer ausgesprochen komplexen königlich-

1 Die Śilāhāras und Yādavas mussten zum Teil die Oberherrschaft der späten Westlichen Cālukyas anerkennen.

2 In all diesen Fällen handelt es sich um Randregionen; eine chronikartige Literatur stammt auch aus Nepal und Assam. Vgl. Michael Witzel, Das Alte Indien (Beck'sche Reihe Wissen 2304), München 2003, 122; Heinz BecherT, Zum Ursprung der Geschichtsschreibung im indischen Kulturbereich (Nachrichten der Akademie der Wissenschaften in Göttingen, Philologisch-Historische Klasse, 1969, 2), Göttingen 1969; Hermann KULKE, Geschichtsschreibung und Geschichtsbild im hinduistischen Mittelalter, in: Saeculum 30 (1979), 100-112. Walter SLAJE, Kaschmir im Mittelalter und die Quellen der Geschichtswissenschaft, in: IndoIranian Journal 48 (2005), 1-70.

3 Im Vergleich zu Steininschriften ist ihre relativ gute Transportabilität ein Spezifikum der Kupfertafelurkunden. Damit waren sie das geradezu prädestinierte Medium für Stiftungen an Brahmanen, deren Charakteristikum in ihrer Mobilität bestand. Die Kupfertafeln waren in der Regel dazu bestimmt, dem Empfänger ausgehändigt und von ihm zum Beweis seiner Rechte an dem Objekt aufbewahrt zu werden. Die Texte wurden vermutlich bei der Übergabe verlesen. Zum Schutz vor Raub wurden die Kupfertafeln dann aber häufig vom Empfänger vergraben.

4 In den Inschriftencorpora der hier betrachteten Herrscherhäuser sind die Genealogie- und Eulogiepassagen in Versen und die Titulaturen und Schenkungsbeschreibungen in Prosa abgefasst.

5 Annette Schmiedchen, Herrschergenealogie und religiöses Patronat. Die Inschriftenkultur der Rāṣtrakūṭas, Śilāhāras und Yādavas (8. bis 13. Jahrhundert) (Gonda Indological Series 17), Leiden 2014a, 460-485. 
fürstlichen Schenkungs- und Stiftungspolitik verbunden. Die Könige wurden als durch dynastische Kontinuität und matrimoniale Beziehungen sowie durch ihre persönlichen Fähigkeiten und Taten für den Thronanspruch qualifiziert dargestellt. Wegen ihrer erfolgreichen Bemühungen, die politisch-moralische Ordnung durch gerechte Herrschaft, durch religiöses Patronat und durch karitative Maßnahmen aufrechtzuerhalten, galt auch der Fortbestand ihrer Regentschaft als legitimiert. Militärische Stärke spielte eine besondere Rolle.

Eine wichtige legitimatorische Funktion kam dabei den von den Herrschern benutzten Titeln (d.h. Statusbezeichnungen) und Epitheta (Bei- oder Schmucknamen) zu. Um die Mitte des 8. Jahrhunderts hatten die Rāṣtrakūṭas die Dynastie der frühen Westlichen Calukyas abgelöst. ${ }^{6}$ Die Rāṣtrakūṭas übernahmen den von ihren Vorgängern eingeführten offiziellen Titel pṛthivi-vallabha, „Liebling der Erde“ ${ }^{7}$ Dies weist darauf hin, dass sie sich als legitime Erben des Calukya-Reiches betrachteten. Gleichzeitig legte sich die Rāṣțrakūta-Hauptlinie auch eine imperiale Titulatur zu. Sie bestand aus den in Indien seit dem späten Altertum, seit der Gupta-Zeit (4.-6. Jahrhundert), überregional benutzten imperialen Titeln $m a-$ hārājādhirāja, „Oberkönig der Großkönige“, parameśvara, „Oberherrscher“, und parama-bhatțāraka „höchster Gebieter“. 8 Aus der Titelwahl geht hervor, welche große Bedeutung die Rāṣțrakūṭas dem endgültigen militärischen Erfolg über die frühen Westlichen Calukyas für ihren Anspruch auf imperiale Hegemonie über den gesamten Subkontinent zumaßen.

Die Prosatitulaturen in den Stiftungspassagen der offiziellen Urkunden sind auch hinsichtlich der Namensgebung bei den Rāṣtrakūṭas äußerst aufschlussreich. Einige Urkunden erwähnen explizit, dass die Rāșțrakūṭa-Könige Hauptnamen (mukhyanāman) und Beinamen (gaunanāman) trugen. ${ }^{9}$ Namen wie Indra, Karka, Kṛṣna, Govinda, Dantidurga, Dhruva ${ }^{10}$ wurden offenbar bei der Geburt an männliche Angehörige der Dynastie vergeben. Anlässlich der Übernahme der Regentschaft scheinen - wie bei anderen mittelalterlichen indischen Herrscherhäusern - diverse Beinamen hinzugekommen zu sein. Dabei setzten die Rāṣtrakūṭa-Könige vermutlich zur selbstdefinitorischen Abgrenzung spezifische Akzente, indem sie sich nicht für Bildungen entschieden, die schon bei

6 Die frühen Westlichen Calukyas hatten vom 6. bis 8. Jahrhundert über weite Teile des Dekkhan geherrscht, wobei das Zentrum ihres Reiches nicht in Maharashtra, sondern im Norden Karnatakas gelegen hatte. - Die Verfasserin unterscheidet zwischen den frühen Calukyas und den späten Cālukyas auch hinsichtlich der Schreibung des Dynastienamens: Calukya/Cālukya; vgl. SchMiedChen 2014a, 7, Anm. 5.

7 SCHMiedCHen 2014a, 41.

8 Ebd., 62. Zu diesen Termini vgl. auch Dinesh Chandra SiRcAR, Indian Epigraphical Glossary, Delhi 1966, 185, 235-237.

9 Schmiedchen 2014a, 39 und Anm. 35.

10 SCHMiedchen 2014a, 27. 
anderen zeitgenössischen indischen Dynastien verbreitet waren. ${ }^{11}$ Typisch für die Rāșțrakūṭas waren Komposita auf ovarșa („Regen“) und `tunga („Gipfel“), die ähnlich wie der Name des Herrschergeschlechts klar die dynastische Identität markierten. Bei der Zuordnung von Epitheta gab es unter den Rāṣțrakūṭas deutliche Ansätze zu festen Namenskombinationen, die unter legitimatorischen Gesichtspunkten wohl auch ein wichtiges Kennzeichen dynastischer Kontinuität darstellten. Besonderer Beliebtheit erfreuten sich vor allem die Epitheta auf ${ }^{\circ}$ varșa, die auf die große Freigebigkeit der Rāṣțrakūṭas und auf die herrscherliche Kraft als ,Regenmacher' sowie - mit DerRett - auf die maskuline Potenz ihrer Könige anspielten. ${ }^{12}$ Diese von den Rāṣțrakūṭas offenbar ,erfundenen' varșaNamen wurden später von anderen Königen übernommen. ${ }^{13}$

Eine legitimatorische Funktion hatte vermutlich auch die zum Ende des 9. Jahrhunderts eingeführte Neuerung, in der Prosatitulatur über eine Formulierung mit ${ }^{\circ} p \bar{a} d \bar{n} n u d h y a \overline{t a}$, „begünstigt durch“, ${ }^{14}$ einen direkten Bezug zum (bereits verstorbenen) Vater bzw. Vorgänger herzustellen, einen Bezug, der wiederum die Rechtmäßigkeit des Anspruchs auf den Thron durch den Verweis auf dynastische Kontinuität unterstreichen sollte. Bezeichnenderweise ist diese Weiterentwicklung der Titulatur zum ersten Mal für Rāṣțrakūṭa Dhruva belegt, einen König, der seinen Machtanspruch gegen seinen älteren Bruder, Govinda II., durchgesetzt hatte. Durch diese bewusste Bezugnahme auf den Vater bemühte sich (der Usurpator) Dhruva darum, mit seiner von den Untertanen wohl positiv aufgenommenen Traditionsverbundenheit den eher negativ bewerteten Kontinuitätsbruch, die Entmachtung des von ebendiesem Vater vorherbestimmten eigentlichen Thronfolgers, in den Hintergrund treten $\mathrm{zu}$ lassen. ${ }^{15}$

Eine noch stärker legitimatorische Funktion für den aktuellen König hatte die der jeweiligen Prosatitulatur vorgeschaltete Genealogie in Versen. Die offizielle Darstellung der Geschichte der Rāșțrakūṭa-Dynastie bestand aus drei Komponenten: [1.] aus der verwandtschaftlichen Positionierung des jeweiligen Regenten im Stammbaum und der damit nachgewiesenen Rechtmäßigkeit seines An-

11 Bei vielen südindischen Dynastien (Pallavas, Kadambas, Westliche Gangas) waren z.B. Namen auf 'varman („Schutz“) üblich; bei den frühen Westlichen Calukyas und den Maitrakas hatten sich Bildungen auf 'āditya („Sonne“) besonderer Beliebtheit erfreut; vgl. Schmiedchen 2014a, 39f. Einzige Ausnahme in dieser Hinsicht ist bei den Rāșțrakūṭas der Name Dantivarman; vgl. ebd., 39, Anm. 36.

12 Duncan M. Derrett, Bhūbharana, bhūpālana, bhübhojana. An Indian Conundrum, in: Bulletin of the School of Oriental and African Studies 22/1 (1959), 108-123. Vgl. auch SCHMIEDCHEN 2014a, 40, 439.

13 John Faithful FLEET, Some Records of the Rashtrakuta Kings of Malkhed. The appellations of the Rāshțrakūṭas of Mālkhed, in: Epigraphia Indica 6 (1900/01), 167-198, bes. 188, Anm. 5.

14 Cédric Ferrier/Judit Törzsök, Meditating on the King's Feet? Some Remarks on the Expression pādānudhyāta, in: Indo-Iranian Journal 51 (2008), 93-113.

15 Schmiedchen 2014a, 75. 
spruchs auf den Thron, [2.] aus einer allgemeinen Lobpreisung der moralischen Integrität des Dynasten und seiner Vorfahren sowie ihrer religiösen Verdienste und ,guten' und gerechten Herrschaft, die sich angeblich über den gesamten Subkontinent erstreckte, sowie [3.] aus der verhältnismäßig konkreten Schilderung von politischen und militärischen Ereignissen, von Bündnissen mit wichtigen Zeitgenossen und noch häufiger von der Überlegenheit über mächtige Gegner.

Die in den offiziellen Sanskrit-Kupfertafelurkunden der Rāṣtrakūṭa-Dynastie überlieferten Genealogien sind selbstverständlich aus der Perspektive dieses Herrscherhauses geschrieben. Dennoch - oder gerade deshalb - blieb die Beschreibung des Stammbaums keinesfalls unveränderlich, sondern wurde immer wieder den innen- und außenpolitischen Erfordernissen angepasst, mitunter sogar mehrmals innerhalb der Regierungszeit eines Königs. Vor allem beim Übergang der Herrschaft auf einen anderen Regenten - und hier insbesondere bei Brüchen in der Thronfolge - ergab sich nicht selten die Notwendigkeit, frühere Aussagen zu tilgen oder abzuwandeln bzw. bestimmte Ereignisse mit einer Art offizieller Erklärung zu versehen. ${ }^{16}$

Es scheint Vorlagen für die Abfassung der Stammbaumbeschreibungen gegeben zu haben. In den Rāșțrakūṭa-Inschriften können acht offizielle Fassungen zur Darstellung der imperialen Linie unterschieden werden; darüber hinaus gab es einen Entwurf für die Genealogie der Seitenlinie von Gujarat. ${ }^{17}$ Das Gerüst für die jeweilige offizielle Beschreibung der Rāșțrakūṭa-Dynastie bildete deren Stammbaum. Doch bereits aus den zwischen den einzelnen Urkunden differierenden Aufzählungen von aufeinanderfolgenden Regenten gehen Widersprüche und Brüche in der dynastischen Geschichte hervor. Es gab nicht nur einen, sondern mehrere Stammbäume. Im gleichen Maße, wie der aktuelle RāṣțrakūṭaKönig an seiner Verankerung in der Abstammungslinie interessiert war, um seinen persönlichen Herrschaftsanspruch zu legitimieren, war ihm auch daran gelegen, innerdynastische Konkurrenten nicht nur faktisch auszuschalten, sondern überdies aus der urkundlich gepflegten Erinnerung zu bannen. Nicht alle der häufigen Erbfolgestreitigkeiten konnten jedoch durch ein einfaches Ver-

16 Schmiedchen 2014a, 128. Es gibt keine Hinweise darauf, dass die Urkunden früherer Könige unter deren Nachfolgern manipuliert und die darin enthaltenen Genealogien umgeschrieben wurden. Für die Rāștrakūțas liegt ein Beispiel für ein Palimpsest vor, aber dabei handelt es sich um eine Rāșțrakūṭa-Tafel aus dem Jahre 930 n. Chr., die ein halbes Jahrhundert später im Auftrag einer gegnerischen Dynastie ,überprägt' wurde, die zu dieser Zeit die RāșțrakūṭaHauptstadt Mānyakheța erobert hatte; ebd., 207.

17 Unter den Śiāhāaras und Yādavas ist das Bild uneinheitlicher. Neben Schilderungen, die bisher nur je einmal nachgewiesen sind, finden sich auch bei ihnen mehrfach belegte Vorlagen. In jeweils mehr als einer Urkunde wurden fünf verschiedene Fassungen der Yādavas, zwei Entwürfe der Śilāhāras von Nord-Konkan und je eine Version der Śilāhāras von SüdKonkan bzw. der Śilāhāras von Kolhapur verwendet; vgl. ebd., 20. 
schweigen aus dem ,offiziellen Gedächtnis` getilgt werden. Insbesondere dann, wenn sich schließlich das Kollateralprinzip durchsetzte, die Thronfolge also nicht auf den ältesten Sohn des vormaligen Königs überging bzw. die Herrschaft nicht dauerhaft in dessen Händen blieb (d.h. wenn sich die Primogenitur nicht durchsetzte), erwähnte der an die Macht gekommene ,Usurpator' den übergangenen Kronprinzen oder Kurzzeitregenten und ließ die Gründe für dessen angebliche Abdankung oder Absetzung erklären bzw. von dem Vorgang eine eigene Version verbreiten. In diesem Zusammenhang wiederkehrende Motive sind Kritik an den angeblichen Schwächen bzw. am Desinteresse des unterlegenen Konkurrenten an der Herrschaftsausübung oder die Unterstellung einer Kollaboration mit feindlichen Mächten. ${ }^{18}$

Beide Argumentationsstränge - moralische Integrität und persönliche Qualitäten sowie das Verhältnis zu den Nachbarkönigen - werden in den Genealogien, freilich mit umgekehrtem Vorzeichen, auch für den aktuellen Regenten und die von diesem zu seinen Vorgängern gezählten Dynasten verfolgt. Für die erste Diskurslinie orientierte man sich an allgemeinen Grundsätzen für ,gutes' Königtum im frühmittelalterlichen Indien, die in der Literatur und der Epigraphik bezeugt sind. Zu den für die Beschreibung ausgewählten Kriterien zählten sowohl militärische Fähigkeiten als auch religiös-karitative Aktivitäten. Da es sich bei diesen - im Unterschied zu den die Herrscherabfolge skizzierenden Strophen häufig um austauschbare bzw. wahlweise einsetzbare Verse handelte, wurden sie bisweilen in verschiedenen Urkunden für unterschiedliche Könige benutzt, und Vasallenfürsten übernahmen solche Beschreibungen zum Teil wörtlich von ihren Oberherren für sich selbst. Aber sogar in diesen Abschnitten sind mitunter allgemeine Sentenzen mit konkreten Reminiszenzen verwoben. Eine solche Praxis unterstreicht das Bemühen um eine Balance zwischen den durch die politische Ideologie vorgegebenen Stereotypen und vielfältigen Anspielungen auf reale historische Ereignisse.

Die Bewertung bestimmter Geschehnisse konnte sich im Laufe der Zeit wandeln. Dies gilt beispielsweise für Heiratsallianzen, denen große Bedeutung in überregionalen Machtgefügen zukam. Dantidurga, der erste Rāștrakūṭa-König, von dem eigene Urkunden überliefert sind, ließ nicht nur seinen Triumph über die frühen Calukyas preisen, sondern verwies auch mit Stolz auf den Umstand, dass er selbst aus der Verbindung eines Rāștrakūṭa-Fürsten mit einer CalukyaPrinzessin hervorgegangen war. ${ }^{19}$ Unter seinen Nachfolgern, die einer Nebenlinie angehörten, ${ }^{20}$ wurde die offizielle Sicht auf diese Vorgänge jedoch bewusst mo-

18 Ebd., 440.

19 Ebd., 58-60, 441.

20 Von Dantidurga ging die Herrschaft auf dessen Onkel Kṛṣna I., einen jüngeren Bruder seines Vaters, über. 
difiziert: Man tilgte die Erinnerung an die matrimoniale Beziehung zu den Calukyas und definierte das Verhältnis zu dieser Dynastie, deren Erbe man immerhin angetreten hatte, ausschließlich über deren Niederlage. ${ }^{21}$

Unter Dantidurga war um die Mitte des 8. Jahrhunderts Genealogievorlage „1“ entworfen worden. Die unmittelbaren Nachfolger von Dantidurga übernahmen deren Grundgerüst. Unter Kṛ̣nạ I. wurde diese Fassung von ihrem ursprünglichen ,Redakteur' sehr stark gekürzt und hinsichtlich der Darstellung des Verhältnisses zu den frühen Westlichen Calukyas - wie erwähnt - modifiziert. Zu einer wesentlich radikaleren Veränderung kam es, als Govinda III. am Beginn des 9. Jahrhunderts den Entwurf „2“ in Auftrag gab. Diese neue Version setzt erst mit König Kṛ̣na I., dem Großvater von Govinda III., ein und lässt Dantidurga unerwähnt. ${ }^{22}$ Eine solche Verfahrensweise ist wohl nur mit dem Umstand zu erklären, dass nach König Dantidurga mit Kṛ̣ṇa I. der Bruder seines Vaters den Thron bestiegen hatte und es so zu einer Form dessen gekommen war, was als „collateral oppression“ bezeichnet wird. ${ }^{23}$ Mit dem Übergang von der Linie Indras II. und seines ältesten Sohnes, Dantidurga (Primogenitur), auf die Kṛ̣nas I. (Sekundogenitur) war eigentlich eine Seitenlinie an die Macht gekommen. Doch Seitenlinien, denen es gelang, sich fest zu etablieren, betrachteten sich dann als rechtmäßige Hauptlinie und den jeweiligen alten, ,ausgestorbenen' Hauptzweig als Nebenzweig, d.h. als kollateral. Die Erinnerung an solche von Haupt- zu Seitenlinien mutierten Zweige wurde in den späteren Überlieferungen einer erst durch Sekundogenitur entstandenen, aber historisch erfolgreicheren neuen Hauptlinie häufig getilgt. ${ }^{24}$

Die zeitgenössischen Fürsten der ,offiziellen' Seitenlinie von Gujarat hingegen blieben bei Version „1“, in der Dantidurga weiterhin berücksichtigt wurde. $\mathrm{Zu}$ dieser Fortführung der Tradition könnte sie unter anderem bewogen haben, dass es sich bei ihnen um Vertreter einer Nebenlinie handelte, ${ }^{25}$ die zwar die Oberherrschaft des Zweiges, der sich durchgesetzt hatte, anerkennen musste, jedoch nicht daran interessiert war, die Erinnerung an innerdynastische Verzweigungen zugunsten einer monolinearen Idealisierung zu unterdrücken.

Im 10. Jahrhundert kam es zu umfangreichen Ergänzungen der Genealogie, weil man die angebliche Anbindung der historischen Rāṣțrakūṭas an das soge-

21 Ebd., 61, 441.

22 Ebd., 63. Die Bezeichnung der einzelnen Versionen mit „1“, „2“, „3“ usw. stammt von der Autorin.

23 David Henige, Some Phantom Dynasties of Early and Medieval India. Epigraphic Evidence and the Abhorrence of a Vacuum, in: Bulletin of the School of Oriental and African Studies 38 (1975), 525-549.

24 SCHMiedCHEN 2014a, 63.

25 Ebd., 16, 27, 33f., 63. Die Etablierung dieser Seitenlinie im 9. Jh. in Gujarat geht nur aus deren eigenen Urkunden hervor; in den Inschriften der Hauptlinie findet sie hingegen keine Erwähnung; vgl. ebd., 90. 
nannte Mondgeschlecht und an die von diesem abgeleiteten mythischen Yādavas detailliert auszuführen begann. Damit wurde die Mythologie für die gesamte Geschichte des Herrscherhauses legitimatorisch stärker als durch die zuvor und auch weiterhin üblichen Vergleiche einzelner Könige mit Göttern und mythologischen Figuren nutzbar gemacht. ${ }^{26}$

Im Folgenden sollen anhand ausgewählter Beispielstrophen die Leitbilder für ,gute' Herrscher betrachtet werden, wie sie in den Rāṣțrakūṭa-Genealogien entworfen wurden.

[1.] Strophe für Karka I., den Großvater von Dantidurga, aus Vorlage „1“:

yasmin praśāsati mahīn narape dvijānām

vaitānadhūmanicayaị parikarburāṇi /

sandhyāsu saudhaśikharāṇi vilokya kekāh

kurvanti veśmaśikhino jaladāgamotkāḥ //1.6// $/^{27}$

„Als dieser König die Welt regierte, da machten in der Dämmerung die Hauspfauen, wenn sie die durch die Opferrauchwolken der Brahmanen grau verfärbten Palastzinnen sahen, ein Geschrei, als glaubten sie, dass Regenwolken heranzögen [1.6].“

Dies ist eine Anspielung auf den Idealzustand der Gesellschaft, in dem die Brahmanenpriester viele Opfer darbringen. Karka I. wird mit dieser Beschreibung seines Palastes (indirekt) als ,guter ' König und als Garant für den Bestand des Brahmanentums charakterisiert.

[2.] Strophen für Kṛ̣nạa I., den Onkel und Nachfolger des Dantidurga, aus Vorlage "1“:

tasmin divaṃ prayāte vallabharāje [kșataprajābādhah] /

śrìkarkarājasūnur mahīpatih kṛ̣ṇarājo [']bhūt //1.20//28

„Als dieser Vallabharāja (= Dantidurga) gestorben war, wurde Kṛṣna [I.], der Sohn des Śrī-Karkarāja, ein König, der die Not der Untertanen beseitigt hat [1.20].“

viṣameșu viṣamaśīlo yas tyāgamahānidhir daridreșu /

kāntāsu vallabhatarah khyātah praṇateṣu śubhatungah $/ / 1.22 \mathrm{~A} / /^{29}$

26 Ebd., 50 f., 128.

27 Ebd., 57. Diese Strophe ist nur in zwei Urkunden belegt; ebd., 32, Tab. 1. Zu der Strophe vgl. z. B. Devadatta R. BHANDARKar, Dhulia Plates of Karkaraja; Saka-Samvat 701, in: Epigraphia Indica 8 (1905/06), 182-187.

28 Schmiedchen 2014a, 66. Die Zählung dieser und der folgenden Strophen stammt von der Autorin. Diese Strophe findet sich in diversen Urkunden; vgl. z.B. H. S. Tноsar/A. A. Hingmire, Barsi Plates of Krishna I, in: Journal of the Epigraphical Society of India 11 (1984), 106-113.

29 SCHMIEDCHEN 2014a, 67. 
„Er ist berühmt als einer von grimmigem Charakter gegenüber den Grimmigen, als ein Hort der Freigebigkeit gegenüber den Armen, als ein großer Liebhaber (vallabhatara) gegenüber den Geliebten [und] als ein ,Glücksgipfel' (śubha-tunga) gegenüber den Untertanen $[1.22 \mathrm{~A}] . “$

suhṛdi dhanam ripuṣu śarām yuvatijane kāmam aśaraṇe śaraṇam / yah santatam abhivarșann akālavarșo bhuvi khyātah $/ / 1.23 \mathrm{~A} / /^{30}$

„Er ist in der Welt bekannt als ,einer, der es [auch] zur Unzeit (= zu jeder beliebigen Zeit) regnen lässt' (akāla-varșa), der auf den Freund Reichtum, auf die Feinde Pfeile, auf die Jungfrauen Liebe, auf den Schutzlosen Schutz stets herabregnen lässt [1.23A].“

ullamghitama[r]yāde kalijaladhau vyākulā nimajjantī /

$y[e]$ noddhrtā dhar[i]trī śrīpralayamahāvarāheṇa $/ / 1.24 \mathrm{~A} / /^{31}$

„Durch diesen ,großen Eber (mahā-varāha) des Weltuntergangs` wurde die durcheinander geratene Erde, die im über die Ufer getretenen ,Ozean des Kali[-Zeitalters] versank, [wieder] herausgehoben [1.24A].“

Die Eulogie von Kṛ̣na I., dessen voller Name Kṛ̣ṇa Akālavarṣa Śubhatunga lautete, enthält nicht nur Anspielungen auf dessen Beinamen, sondern entwirft auch das Bild eines in jeder Hinsicht idealen Herrschers, wozu neben Freigebigkeit, Bündnistreue und militärischer Stärke gehört, dass er als großartiger Liebhaber charakterisiert wird. Zudem ist er als Weltenretter beschrieben, wenn er mit Gott Viṣnu in dessen Inkarnation als Eber verglichen wird, der der Mythologie zufolge die Erde vom Meeresgrund emporhob, auf den sie durch einen Dämon versenkt worden war. Metaphorisch wird hier das ,schlechte Zeitalter (kali-yuga), ${ }^{32}$ in dem nach den geläufigsten indischen Theorien von den vier Weltzeitaltern sowohl die Rāṣţrakūṭas regierten als auch wir heute leben, mit einem Ozean verglichen, in dem die Erde (vor dem Machtantritt von Kṛ̣na I.) versunken gewesen sein soll.

30 Ebd., 67. Eine andere Strophe enthält ebenfalls eine Anspielung auf den Beinamen Akālavarṣa: dīnānāthapranayișu yatheștaceștam samīhitam ajasram / tatkṣaṇam akālavarṣo varșati sarvārti[nirmathanam]] //1.24// „[Dieser] Akālavarșa (= Kṛ̣ṇa I.) lässt für die Schwachen und Schutzlosen sowie für [seine] Freunde sofort [und] unaufhörlich das Begehrte nach Gutdünken regnen, um alle Leiden zu löschen [1.24].“ Vgl. hierzu auch Thosar/Hingmire 1984.

31 Schmiedchen 2014a, 67. Die alternativen Strophen 1.22A-1.24A sind nur in einer Urkunde von Krṣna I. belegt; vgl. ebd., 32, Tab. 1. Zu dieser Urkunde vgl. Vishnu Sitaram SuктнANKAR, Bhandak Plates of Krishnaraja I.: Saka 694, in: Epigraphia Indica 14 (1917/18), 121-129.

$32 \mathrm{Zu}$ diesem schlechtesten aller Zeitalter vgl. Fred VIRKus, Die Könige und das Kaliyuga Bezugnahmen auf die Weltzeitaltertheorie in frühmittelalterlichen Inschriften, in: Beiträge des Südasieninstituts (Humboldt-Universität zu Berlin) 9 (1997), 37-43. Zu anderen Beispielen vgl. SCHMiedCHEN 2014a, 76f., 95, 123. 
[3.] Strophen für Dhruva, den jüngeren Sohn von Kṛ̣ṇa I., aus den Vorlagen „1“ und „2":

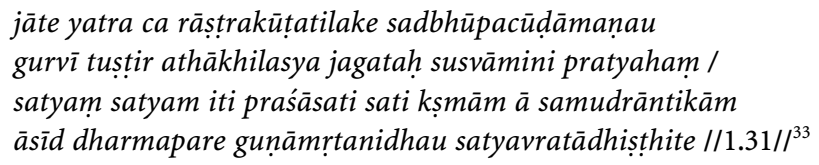

„Und als diese Zierde der Rāṣtrakūṭas zu einem Stirnjuwel der besten Könige geworden war [und] dieser dem dharma Getreue sich als ,Ambrosia-Gefäß` der Tugenden dem Wahrheitsgelübde verschrieben hatte und die Erde bis zur Meeresküste regierte, groß war da tagtäglich die Zufriedenheit über den guten Herrscher (su-svāmin) bei der ganzen Welt[, die ausrief]: ,Die Wahrheit ist fürwahr [zurückgekehrt]‘ [1.31].“

hrșto [']nvaham yo [']rthijanāya [sarvam]] sarvasvam änanditabandhuvargah / prādāt [prarușto] harati sma vegāt prāṇān yamasyāpi nitāntavīryah $/ / 1.33 / /^{34}$

„Wenn er, der seine Verwandten beglückte, erfreut war, gab er Tag für Tag den Bedürftigen all seinen Besitz; wenn er, der außerordentlichen Heldenmut besaß, erzürnt war, raubte er ungestüm selbst das Leben des [Todesgottes] Yama [1.33].“

labdhapratiștham acirāya kalị̣ sudūram

utsārya śuddhacaritair dharanitalasya /

krtvā punah krtayugaśriyam apy aśeșam

citram katham nirupamah kalivallabho [']bhūt //2.9//35

„Wie wunderbar ist es, dass Nirupama (= Dhruva) ein Kalivallabha ${ }^{36}$ wurde, nachdem er das auf der Erde etablierte Kali[yuga] schnell durch [seinen] reinen Lebenswandel sehr weit weg geschafft und auch das Glück des Kṛtayuga völlig wiederhergestellt hatte [2.9].“

Dem König Dhruva, dessen voller Name Dhruva Dhārāvarṣa Nirupama Kalivallabha lautete und der explizit als „guter Herrscher“ (su-svāmin) bezeichnet wird, attestierte man nicht nur Freigebigkeit und Heldenmut, Rechts- und Wahrheitstreue, sondern behauptete auch, dass er „die Erde bis zur Meeresküste regiert", demnach also den ganzen Subkontinent beherrscht habe. Deutlicher als für Kṛṣna I. wird für Dhruva postuliert, er habe das ,schlechte Zeitalter' außer Kraft gesetzt und die Verhältnisse eines, goldenen Zeitalters' (krta-yuga) hergestellt. Ferner ist in der Eulogie des Dhruva bemerkenswert, dass Elemente ,guter' Herrschaft auch seinen Feinden bescheinigt wurden. Interessanterweise geschieht dies in einer Strophe, in der die Schilderung des Sieges über einen gegnerischen König der Westlichen Gañga-Dynastie aus Karnataka mit der

33 Ebd., 73. Diese Strophe findet sich in vier Urkunden; vgl. ebd., 32, Tab. 1.

34 Ebd., 73f. Diese Strophe findet sich in drei Urkunden; vgl. ebd., 32, Tab. 1.

35 Ebd., 76. Diese Strophe findet sich in diversen Urkunden; vgl. ebd., 33, Tab. 2.

36 Zu diesem ungewöhnlichen Epitheton vgl. ebd., 76, Anm. 202; John Faithful FleEt, Nilgund Inscription of the Time of Amoghavarsha I.; A. D. 866, in: Epigraphia Indica 6 (1900/01), 98108, bes. 105, Anm. 9. 
Vertreibung des hier personifiziert dargestellten,schlechten Zeitalters‘verknüpft wird:

\author{
anyair na jātu vijitam guruśaktisāram \\ ākrāntabhūtalam ananyasamānamānam / \\ yeneha baddham avalokya cirāya gaṃam \\ dūram svanigrahabhiyeva kalih prayātah $/ / 2.6 / /^{37}$
}

„Nachdem [Kali] gesehen hatte, dass dieser [Dhruva] den Ganga, der durch andere nie zuvor besiegt worden war, dessen Quintessenz in der Macht der Weisen lag, der die [ganze] Welt erobert hatte [und] dessen Stolz ohnegleichen war, lange festhielt, floh Kali weit weg - wie aus Angst, selbst ergriffen zu werden [2.6].“

Damit ist wohl gemeint, dass sich der Gangga-König - dem Ideal eines indischen Herrschers entsprechend - auf den Rat seiner Lehrer, vor allem des Hofpriesters (purohita), stützte. Der Sieg über einen solchen Kontrahenten wird also nicht nur durch die Beschreibung seiner Stärke überhöht, sondern auch dadurch, dass er als ,guter' Herrscher beschrieben wird.

\title{
[4.] Strophe für Karkarāja, einen Vertreter der Seitenlinie von Gujarat:
}

rājye yasya na taskarasya vasatir vyādheh prasūtir mṛtā durbhikṣam na ca vibhramasya mahimā naivopasargodbhavah / kṣinno doṣaganah pratāpavinatāseșārivargas tathā no vidvatparipanthinī prabhavati krūrā khalānām matịh //G.8// $/^{38}$

„In dessen (= Karkarājas) Reich wohnt kein Dieb, [und] es brechen keine Krankheiten mehr aus. [Dort] gibt es auch keine Hungersnöte, der Wahn hat [seinen] Einfluss [verloren], und ebenso passieren keine Unglücke mehr. Die Übel sind vernichtet, und die Feinde sind restlos unterworfen durch [des Karkarāja] Macht. Nicht regiert mehr der grausame Geist der Schurken, der die Wissenden behindert [G.8].“

Neben Vorstellungen, die die zeitgenössischen Leitbilder der, guten' Herrschaft illustrieren, enthalten die Rāṣtrakūṭa-Genealogien auch Informationen dazu, auf welche Weise und mit welchen Mitteln die konkrete Machtausübung erfolgte. Vier Grundpfeiler scheinen dabei eine besondere Rolle gespielt zu haben: [1.] die Präsenz des Herrschers, [2.] Heiratsallianzen, [3.] Vasallitäts- und Subvasallitätsbeziehungen sowie [4.] ein gezieltes königliches Patronat. Die Rāṣțrakūṭas waren über zwei Jahrhunderte lang äußerst erfolgreich in ihrem Bemühen, ihr großes zentralindisches Reich durch eine Hegemonialpolitik zu konsolidieren, die sich auf eine starke persönliche Machtpräsenz des jeweiligen Herrschers, auf

37 Schmiedchen 2014a, 76f. Diese Strophe findet sich in diversen Urkunden; vgl. z. B. P. L. Gupt A, Nesarika Grant of Govinda III, Saka 727, in: Epigraphia Indica 34 (1961/62), 123-134.

38 Schmiedchen 2014a, 91. Die Strophe findet sich in drei Urkunden; vgl. z. B. Moreshwar G. Dikshit, Prince of Wales Museum Plates of Govindaraja: Saka 732, in: Epigraphia Indica 26 (1941/42), 248-255. 
Vizekönige in Gujarat und Karnataka, die vorzugsweise der eigenen Dynastie entstammten, und auf die Ansiedlung von Brahmanen in fast allen Teilen Maharashtras stützte.

[1.] Nicht zu unterschätzen für den Machterhalt der Rāșțrakūțas war offenbar die Präsenz ihres aktuellen Regenten und seiner unmittelbaren Vertreter. Die von den Rāṣțrakūṭa-Königen verfügten Stiftungsurkunden geben in der Regel Auskunft über deren Aufenthaltsorte zum Zeitpunkt der von ihnen vorgenommenen Dotationen. Auffällig ist dabei, dass besonders in der Frühzeit in dem Zusammenhang häufig der Terminus vijaya-skandhāvāra, „Siegeslager“, auftaucht, der ursprünglich ein temporäres Heerlager, später auch einen Wohnstützpunkt für den reisenden König bezeichnete. ${ }^{39}$ Einer verbesserten ,Präsenz ' der RāṣṭakūṭaHerrscher sollte wohl auch die Verlagerung ihrer Hauptstadt aus dem Nordwesten von Maharashtra nach Mānyakheța in Nordost-Karnataka dienen. ${ }^{40}$ Interessant ist ferner, dass die Urkunden stets die Versicherung enthalten, der Herrscher erfreue sich bester Gesundheit, er sei kuśalin. ${ }^{41}$

[2.] In der 2. Hälfte des 9. Jahrhunderts kam es zu geradezu systematischen Heiratsallianzen der Rāṣțrakūṭas. Die Ehe von Kṛ̣ṇa II. mit einer Kalacuri-CediPrinzessin bildete den Auftakt zu einer Reihe matrimonialer Beziehungen ${ }^{42}$ zwischen den Rāṣtrakūṭas und den Kalacuri-Cedis (östliches Madhya Pradesh). Jagattunga II., der Sohn von Kṛṣna II., war sogar mit zwei Kalacuri-Prinzessinnen verheiratet; aus diesen Verbindungen ging jeweils ein Sohn hervor. Der KalacuriCedi-König Kokkalla ließ sich in einer seiner Inschriften dafür preisen, „zwei Ruhmessäulen errichtet“ zu haben - im Süden Kṛ̣ṇarāja (= Rāṣțrakūṭa Kṛ̣ṇa II., seinen Schwiegersohn) und im Norden Bhojadeva (= Gurjara-Pratihāra Bhoja II.). ${ }^{43}$ Zwischen den Rāṣṭakūṭas und den Gurjara-Pratihāras bestand eine traditionelle Feindschaft. ${ }^{44}$ Durch die parallelen Beziehungen der Rāṣțrakūṭas und der Gurjara-Pratihāras zu den Kalacuri-Cedis könnte es zwischen diesen beiden Konkurrenten zu einer zeitweiligen Beruhigung in den Auseinandersetzungen gekommen sein. Mindestens aber wollten die Rāṣțrakūṭas wohl durch die enge

39 Schmiedchen 2014a, 65, 68, 69, 79, 118, 130-133, 462, 466, 468, 470, 472. Zu dem bedeutungsgleichen jaya-skandhāvāra vgl. SirCAR 1966, 134. Zur Kurzform skandhāvāra vgl. ebd., 314.

40 Schmiedchen 2014a, 8, 98, 132, 442.

41 Ebd., 139. Eine solche Formulierung war in den königlichen Stiftungsurkunden vieler Dynastien üblich.

42 Vgl. hierzu ebd., 99f., 106f., 108, Abb. $3 \mathrm{f}$.

43 Vasudev Vishnu Mirashi, Inscriptions of the Kalachuri-Chedi Era (Corpus Inscriptionum Indicarum 4), Ootacamund 1955, Nr. 45: Bilhari-Inschrift, Strophe 17.

44 Vgl. hierzu Schmiedchen 2014a, 54, 64f., 76-78, 83, 86-88, 91. 
persönliche Verbindung erreichen, dass die Kalacuri-Könige nicht einseitig zugunsten der Gurjara-Pratihāras in den Konflikt eingriffen. ${ }^{45}$

[3.] Seit dem frühen 9. Jahrhundert ging mit der Ausweitung der tatsächlichen Einflusssphäre und der Stärkung ihres hegemonialen Anspruchs einher, dass sich die Rāșțrakūṭas in ihrer Herrschaftsausübung sehr viel mehr als zuvor auf Vasallitätsbeziehungen stützen mussten. Insbesondere die Genealogievorlage „3“ verdeutlicht, welche strategisch-machtpolitischen Überlegungen das sich stets verändernde Verhältnis zu den Vasallen bestimmten. Immer wieder neu stellte sich offenbar die Frage, ob man in eroberten Territorien (a) Angehörige der eigenen Dynastie einsetzen, (b) die ehemaligen Könige, wenn sie die Oberherrschaft der Rāșțrakūṭas anerkannten, bestätigen oder aber (c) auf neu emporkommende regionale Eliten zurückgreifen sollte. Die Genealogie „3“ beschreibt, wie Govinda III. - geradezu idealtypisch - mit abtrünnigen Vasallen verfuhr, die sich verfeindeten Herrschern angeschlossen hatten: Er bekämpfte sie, nahm sie gefangen, ließ sie „bei Beendigung ihrer Feindschaft" frei und akzeptierte diese ehemaligen Gegner dann wieder als untergebene Fürsten. ${ }^{46}$ Doch nur wenige Beispiele für konkretes Handeln gemäß diesen Überlegungen werden in den offiziellen Darstellungen der Rāșțrakūṭas thematisiert. Selbst eine weitreichende politische Veränderung wie die Etablierung der Rāṣtrakūṭa-Seitenlinie von Gujarat im 9. Jahrhundert, die als Puffer gegen die nordindischen Gurjara-Pratihāras dienen sollte, ist lediglich aus den Urkunden dieser Seitenlinie, nicht aber aus denen der Hauptlinie bekannt. ${ }^{47}$ Von anderen Vasallen liegen nur dann Erkenntnisse vor, wenn sie eigene Urkunden verfügt oder Stiftungen beim König erwirkt haben. ${ }^{48}$ Aus Maharashtra, dem Kerngebiet der Rāṣṭrakūṭas, existieren jedoch kaum Belege für das selbständige Agieren von Gebietsfürsten zu dieser Zeit.

Angesichts der Bedeutung, die die Vasallitätsstrukturen für den Fortbestand mittelalterlicher Regionalreiche besaßen, ist es nicht verwunderlich, dass - anders als die Stabilisierung von herrscherlicher Macht - deren Gefährdung und Verlust sowie Krisen fast ausschließlich in militärischem Kontext und durch Konfrontation mit gegnerischen Fürstenallianzen erklärt werden. ${ }^{49}$ Auch für den Untergang des Rāṣṭrakūṭa-Reiches spielten Vasallen offenbar eine entscheidende Rolle: So wie um die Mitte des 8. Jahrhunderts die frühen Westlichen Calukyas

45 Andererseits könnte die Tatsache, dass es sich bei den in den Genealogien als Brüder dargestellten Mitgliedern der Dynastie häufig um Halbbrüder handelte (ebd., 123, Anm. 412), Thronfolgestreitigkeiten befördert haben.

46 Ebd., 87-89.

47 Ebd., 86, Anm. 251.

48 Zu Beispielurkunden für dieses Phänomen vgl. ebd., 473, RāUr 41; 477, RāUr 53; 481 f., RāUr 65.

49 Ebd., 31, 71, 84, 88. 
von ihren ehemaligen Rāṣțrakūṭa-Vasallen entmachtet worden waren, wurde der Untergang des Rāștrakūṭa-Reiches am Ende des 10. Jahrhunderts mit einer vernichtenden Niederlage gegen einen Fürsten namens Taila aus der neu emporkommenden späten Westlichen Cālukya-Dynastie eingeleitet. Diese Ereignisse sind - naturgemäß - nicht mehr in den Inschriften der Rāṣṭakūtas überliefert, sondern nur in denen der Śilāhāras, einer Nachfolgedynastie. ${ }^{50}$

[4.] Ein wesentlicher Aspekt der Rāșțrakūṭa-Inschriften ist bisher noch nicht zur Sprache gekommen, obwohl dieser per se das Hauptanliegen der Urkunden darstellte, und zwar die darin dokumentierten religiösen Stiftungen der Herrscher. An königlichen Stiftungen aber lässt sich die Überlagerung personeller und transpersoneller Elemente vormoderner Macht und Herrschaft besonders gut illustrieren. Nach dem Befund der Urkunden stifteten fast alle frühmittelalterlichen indischen Dynastien der Periode bis zum 10. Jahrhundert überwiegend zugunsten von Veda-gelehrten Brahmanen ohne klar nachweisbare śivaitische, viṣnuitische oder anderweitige sektarische Affiliation und ohne Tempelbindung. ${ }^{51}$ Nur in viel geringerem Umfang förderten sie buddhistische und jinistische Klöster sowie hinduistische Tempel. Auch drei Viertel der von den Rāṣţrakūṭas verfügten Kupfertafelurkunden galten brahmanischen Empfängern, und nur ein Viertel dieses Corpus beurkundet Dotationen zugunsten religiöser Institutionen, hinduistischer Tempel, jinistischer Heiligtümer sowie buddhistischer Klöster. ${ }^{52}$ D.h., wie eine Reihe ihrer Zeitgenossen unterstützten die Rāșţrakūṭa-Könige vor allem die überregionalen Garanten der Legitimation ihrer Herrschaft, die Veda-gelehrten Brahmanen, die für sie unter anderem auch ihre Genealogien verfassten.

Die Urkunden der Rāṣțrakūṭas zeichnen - ebenso wie die der meisten frühmittelalterlichen indischen Dynastien - ein durchaus ambivalentes Bild von den religiösen Bekenntnissen und vom stifterlichen Handeln der Herrscher. Die Inschriften enthalten sowohl Anrufungen an und Lobpreisungsverse für verschiedene Gottheiten und Vergleiche der Könige und Königinnen mit bestimmten Göttern und Göttinnen als auch viele Details zu deren religiösen Aktivitäten. Diese Angaben sind in ihrer Ausrichtung vielschichtig und ergeben kein homogenes Bild, offenbaren jedoch häufig eine Diskrepanz zwischen persönlicher religiöser Positionierung und staatsmännischem Handeln der Herrscher. Könige ließen sich als Anhänger des Śiva oder des Viṣnu beschreiben, ${ }^{53}$ streuten

50 Ebd., $126 \mathrm{f}$.

51 Annette Schmiedchen, Art. 3. Typologisierungen. 3.6. Indien, in: Michael Borgolte (ed.), Enzyklopädie des Stiftungswesens in mittelalterlichen Gesellschaften, Bd. 1: Grundlagen, Berlin 2014b, 229-248, bes. 241.

52 Schmiedchen 2014a, 158.

53 Zum Gebrauch religiöser Epitheta unter verschiedenen indischen Dynastien (nicht unter den Rāștrakūțas!) vgl. Annette Schmiedchen, Religious Patronage and Political Power. The 
jedoch ihr Patronat ganz auffällig - wenn auch nur selten in je gleichem Umfang zugunsten verschiedener religiöser Gruppierungen, d.h. zugunsten von Brahmanen, hinduistischen Tempeln und/oder buddhistischen Klöstern. Dieser Befund lässt vermuten, dass die Herrscher Stiftungen nicht einzig und allein um des Erwerbs persönlichen religiösen Verdienstes (punya) willen, ${ }^{54}$ sondern auch aus anderen Motiven tätigten: Bei der Vergabe von (öffentlichen) Steuerpfründen agierten sie wohl in erster Linie als ,Amtsträger' und demzufolge aus machtpolitischem Kalkül. Durch solche frommen Stiftungen wollten sie sich vermutlich der Loyalität unterschiedlicher religiöser Strömungen versichern und auch deren weltliche Unterstützer zufriedenstellen.

Zahlreich sind die Belege dafür, dass königliche Stiftungen auf Bitte von Vasallenfürsten und anderen Personen aus dem höfischen Bereich zustande kamen. Dies gilt vor allem für Unterhaltsstiftungen an Tempel und Klöster, die von hohen Amtsträgern gegründet worden waren. In 14 der 75 bekannten Stiftungsurkunden der Haupt- und der Seitenlinie der Rāṣțrakūṭa-Dynastie heißt es, dass die betreffende Dotation „auf Bitte“ (meist vijñāpanayā/vijñāpanena) der Königin, eines Prinzen oder eines Vasallen beziehungsweise einer oder mehrerer lediglich namentlich genannter Personen getätigt wurde. ${ }^{55}$ Umgekehrt erfolgten fünf Stiftungen von Dörfern durch Angehörige der Rāṣtrakūṭa-Dynastie und durch deren Vasallenfürsten „mit der [ausdrücklichen] Zustimmung“ (anumatyā/anumatena) des aktuell regierenden Herrschers. ${ }^{56}$ In einer Kupfertafelurkunde von Govinda III., die eine Dorfstiftung dieses Rāșțrakūṭa-Königs an 13 Brahmanen bezeugt, heißt es am Ende, dass dieses Dokument „auf Befehl [ $\bar{a}$ jñayā] des Herrschers [und] mit dem Einverständnis [anumatena] der Königin“ aufgesetzt worden sei. ${ }^{57}$

Dieses Phänomen, potentiell divergierende Kräfte durch eine vielschichtige Dotationspolitik in das Machtgefüge einzubinden, war aber keinesfalls auf die Rāṣțrakūṭa-Dynastie beschränkt. Ähnliche Patronatsmuster unter den ostindischen Pāla-Königen hat Ryosuke Furui wie folgt bewertet: „Such activities by the subordinate rulers can be interpreted as attempts to encroach legitimately upon

Ambivalent Character of Royal Donations in Sanskrit Epigraphy, in: Journal of Ancient Indian History 27 (2010/11), 154-166.

54 Annette Schmiedchen, Art. 7. Religiöses Verdienst und weltliche Ambitionen. 7.6. Indien, in: Michael Borgolte (ed.), Enzyklopädie des Stiftungswesens in mittelalterlichen Gesellschaften, Bd. 2: Das soziale System Stiftung, Berlin 2016, 72-85, bes. 80.

55 Schmiedchen 2014a, 462f., RāUr 8-10; 467f., RāUr 24-26; 469, RāUr 28; 470, RāUr 32; 471, RāUr 36; 472f., RāUr 39f.; 475, RāUr 46; 477, RāUr 53; 481f., RāUr 65. In RāUr 8 wird auf die ,Wünsche' von insgesamt drei Personen Bezug genommen.

56 Ebd., 460, RāUr 1; 465, RāUr 18; 476, RāUr 49; 478, RāUr 55; 481 f., RāUr 65.

57 Ebd., 466, RāUr 21. Die Gründe dafür, warum die Königin zuzustimmen hatte, werden nicht erklärt. Zu der Urkunde selbst vgl. Vasudev Vishnu Mirashi/L. R. KulKarni, Anjanavati Plates of Govinda III: Saka Year 722, in: Epigraphia Indica 23 (1935/36), 8-18. 
royal authority in the name of pious deeds. Furthermore, the construction of religious institutions on a massive scale may have exhibited their power to local residents and enhanced their authority in rural society ${ }^{\text {“58 }}$

Während Vertreter der regionalen Eliten religionspolitische Akzente durch die Gründung von Tempeln und Klöstern setzten, die zwangsläufig eine ausgeprägte Ortsgebundenheit besaßen, waren Herrscher mit überregionalen Machtansprüchen für eine weitreichende Ansiedlung von Brahmanen in Indien verantwortlich und trugen durch Stiftungen bewusst zu nachhaltigen Migrationen von Gelehrten und zur Verbreitung bestimmter Texttraditionen bei..$^{59}$ Brahmanen wirkten als Mittler spezifischer religiöser Konzepte, als Spezialisten zur Durchführung von Lebenszyklusritualen und als Träger entwickelter Rechtsnormen und Sozialvorstellungen und besaßen die Fähigkeit, diese an das jeweilige Umfeld anzupassen. Somit bildeten sie ideale Stützen des mittelalterlichen Königtums, gerade auch im ländlichen Bereich.

Indische Herrscher hatten jedoch nicht nur Zugriff auf das Kronvermögen, sondern verfügten auch über Privatbesitz, den sie für eigene Stiftungen einsetzen konnten. Insbesondere bei den seltenen Eigengründungen von Klöstern und Tempeln durch Könige fällt es mitunter schwer, anhand der vorhandenen Quellen eine Differenzierung zwischen dem ,Amtsträger' und der ,Privatperson ${ }^{`}$ vorzunehmen. Einiges spricht dafür, dass Könige bei der Etablierung religiöser Institutionen eher als bei Unterhaltsstiftungen den durch ihr eigenes religiöses Bekenntnis vorgegebenen Präferenzen folgten.

Nicht nur die königlichen Stiftungen selbst, sondern auch die administrativen Vorgaben der Urkunden spielten in regionalen Machtgefügen eine wichtige Rolle und wurden mitunter wohl mit normgebender Absicht formuliert. Dies gilt vor allem für Dorfverleihungen, die in den Randgebieten vorgenommen wurden, in denen die Fiskalhoheit des fernen Herrschers häufig eine rein theoretische war und in der Praxis nicht immer leicht durchsetzbar gewesen sein dürfte. Dadurch, dass in den Kupfertafelinschriften sehr detailliert die künftigen Rechte der Begünstigten und die Abgaben, die ihnen zustanden, aufgeführt wurden, bemühte man sich vermutlich darum, einheitliche Maßstäbe für die gesamte Umgebung der Dörfer zu setzen. ${ }^{60} \mathrm{Im}$ Rahmen der Vergabe von Steuerpfründen an religiöse

58 Ryosuke FUrUI, Indian Museum Copper Plate Inscription of Dharmapala, Year 26. Tentative Reading and Study, in: South Asian Studies 27/2 (2011), 145-156, hier: 151.

59 Annette SchmiedCHen, Brahmanische Wanderungsbewegungen im mittelalterlichen Indien. Gewinner und Verlierer, in: Zeitschrift für Geschichtswissenschaft 63/3 (2015), 227-236. In Tausenden heute bekannten Kupfertafelurkunden sind Tausende Brahmanen erwähnt. Mitunter gingen einzelne Stiftungen an mehrere Hundert Brahmanen, wobei nur in einem Teil dieser Urkunden alle Destinatäre namentlich aufgeführt werden.

60 Hermann Kulke, Some Observations on the Political Functions of Copper-Plate Grants in Early Medieval India, in: Bernhard KöLvER (ed.), Recht, Staat und Verwaltung im klassischen Indien, München 1997, 237-243. 
Empfänger formulierte man diese Rechte und Ansprüche und delegierte sie gleichzeitig an Dritte, die lokal ansässig waren oder angesiedelt wurden. ${ }^{61}$

Bei den Rāșțrakūṭas hatten religiöse Stiftungen auch insofern eine legitimatorische Funktion, als sie nicht selten anlässlich der Krönung von Königen emittiert wurden. Von Indra III. sind bisher fünf persönlich vorgenommene Stiftungen belegt, die alle dasselbe Datum tragen, den Tag seiner Krönung (patțabandha, ,[Stirn-]Schmuckbinden'), die an einem Freitag, dem 7. Tag (tithi) der hellen Hälfte des Monats Phālguna im Śaka-Jahr 836 (= 24.2.915 n. Chr.), stattgefunden haben soll. ${ }^{62}$ Auch Govinda IV., der Sohn von Indra III., verfügte eine Stiftung am Tag seiner pattabandha-Zeremonie. ${ }^{63}$ Die Krönungsrituale wurden von beiden Königen offenbar zum Anlass für eine Art Bestandsaufnahme im dynastischen Stiftungswesen genutzt. Durch eine summarische Bestätigung der Stiftungen früherer Herrscher verknüpfte der Regent seine Handlungen mit denen seiner Vorgänger und erwarb sogar einen Teil des mit diesen Dotationen verbundenen religiösen Verdienstes. Die fünf Urkunden von Indra III. scheinen diese Vorgänge als einen Prozess wiederzugeben, bei dessen Fortschreiten mehrere Stadien der Erfassung und auch Bekräftigung früherer Stiftungen dokumentiert wurden. ${ }^{64}$

Die Śilāhāras und Yādavas, die in Maharashtra das Erbe der Rāṣṭrakūṭas antraten, standen zwar hinsichtlich ihrer Herrschaftsstrategien und ihrer Patronatspolitik in der Tradition der Vorgängerdynastie, doch seit dem Untergang des Rāșțrakūṭa-Reiches in der zweiten Hälfte des 10. Jahrhunderts vollzogen sich grundlegende Veränderungen hinsichtlich der Beteiligung regionaler und lokaler Eliten an der Machtausübung sowie bezüglich der Ausrichtung und des Charakters religiöser Stiftungen.

Die Śilāhāras und frühen Yādavas trugen im Unterschied zu den Rāṣtrakūṭas Vasallen- und Regionalfürstentitel. Deren Verwendung zeigt, dass die in Maharashtra regierenden Dynastien vom 10. bis zum 12. Jahrhundert die nominelle Oberherrschaft eines anderen Königshauses anerkennen mussten, und zwar die der in Nord-Karnataka herrschenden späten Westlichen Cālukyas. Die Tatsache, dass die Vasallentitulaturen aber nur selten direkte Hinweise auf die Cālukyas

61 Schmiedchen 2016, 81. Ein großer Teil der in Stiftungen erwähnten brahmanischen Destinatäre wird als aus anderen Gebieten zugewandert (vinirgata) bezeichnet; vgl. DiEs. 2014a, 165f., 172-174; DiEs. 2015, 229-231.

62 Schmiedchen 2014a, 37, 103, 207.

63 Ebd., 111, 133, 209, 211f. Zu dieser Urkunde vgl. Devadatta R. Bhandarkar, Cambay Plates of Govinda IV.; Saka-Samvat 852, in: Epigraphia Indica 7 (1902/03), 26-47.

64 In Urkunde RāUr 60 ist lediglich davon die Rede, dass die früher vergebenen Dörfer Einnahmen in Höhe von 500.000 dramma generierten. In RāUr 61-62 werden 400 Dörfer mit 2.050.000 dramma erwähnt, in RāUr 63-64 dann 650 Dörfer mit (allerdings nur) 2.100.000 [dramma]; vgl. SCHMiEdCHEN 2014a, 210. 
enthalten, verdeutlicht das Bemühen um eine Distanz zu den Cālukya-Oberherren. Erst nach dem Untergang der späten Westlichen Cālukyas benutzten die Yādava-Könige eine imperiale Titulatur (samastabhuvanāśraya śrī-prthvī-vallabha mahārājādhirāja parameśsara parama-bhațtāraka śrīmat-pratāpa-cakravartin), die sich an der der Cālukyas orientierte. ${ }^{65}$ Die Übernahme imperialer Titel ging jedoch nicht immer mit einem tatsächlichen Territorial- und Machtzuwachs einher. So benutzten die späten Śilāhāra-Fürsten von Nord-Konkan am Ende des 12. und zu Beginn des 13. Jahrhunderts immer gewichtigere Titel (wie mahārājādhirāja), obwohl sie kontinuierlich an Einfluss verloren. ${ }^{66}$

Durch einen Glücksfall der Überlieferung lässt sich der historische Stammbaum der frühen Yādavas nicht nur aus den Genealogiepassagen ihrer Kupfertafelurkunden, sondern auch aus der Einleitung eines literarischen Textes, des ,Vratakhaṇ̣a'-Abschnitts einiger Manuskripte des ,Caturvargacintāmaṇi‘ von Hemādri, rekonstruieren, eines kompilatorischen Werkes zu purānisch-hinduistischen Riten. ${ }^{67}$ Die verschiedenen inschriftlich belegten Genealogien („YY 1“ bis „Y $3^{\prime \prime) ~ e r w e c k e n ~ d e n ~ E i n d r u c k, ~ a l s ~ h a b e ~ e s ~ s i c h ~ i m ~ w e s e n t l i c h e n ~ u m ~ e i n e ~}$ fortgesetzte idealtypische Vater-Sohn-Linie gehandelt, auch wenn - anders als bei den Rāștrakūtas - eindeutige Bezeichnungen für dieses Verwandtschaftsverhältnis ersten Grades (wie z. B. tanaya, putra, suta, sūnu) selten vorkommen. Häufig wird die Verknüpfung der einzelnen Dynasten nur mit „von diesem stammte ab ..." (tasmād abhüt/abhavat ...) hergestellt. Selten finden sich direkte Hinweise darauf, dass die idealtypische Erbfolge vom Vater auf den jeweils ältesten Sohn unterbrochen wurde. ${ }^{68}$

Die Genealogie der frühen Yādavas bei Hemādri unterscheidet sich in einigen Punkten von der in den eigenen Urkunden dieser Dekkhan-Dynastie. Die Informationen des Hemādri sind weniger detailliert, oft sogar ausgesprochen kursorisch. Dennoch erscheinen bei ihm mehr Familienmitglieder der frühen Yãdavas als in deren offiziellen Urkunden, und die dynastische Verbindung der frühen mit den späten Yādavas ist geradezu ,lückenlos' geklärt. Es stellt sich daher die Frage, ob bei Hemādri eine Version des Stammbaums wiedergegeben ist, welche die aus verschiedenen Gründen entstandenen Tradierungslücken nachträglich zu füllen suchte, oder ob - umgekehrt - in den Yādava-Urkunden Brüche der tatsächlichen Fürstenfolge durch gezielte Auslassungen in der Dar-

65 Ebd., 438. Der Titel samastabhuvanāśraya bedeutet in etwa „Schirm[herr] der ganzen Welt"; śrimat-pratāpa-cakravartin (wie bereits cakravartin allein) steht für „Weltherrscher“; vgl. SIRCAR 1966, 65, 257.

66 SCHMiEdChen 2014a, 235.

$67 \mathrm{Zu}$ diesen Genealogien (Rājapraśasti I und Rājapraśasti II) vgl. Ramakrishna G. BHANDARKAR, Appendix C, in: Ders., Early History of the Deccan and Miscellaneous Historical Essays (Reprint of Collected Works 3), Pune 1983, 191-198.

68 SCHMiedChen 2014a, 327. 
stellung geglättet wurden. Da sich die Angaben der beiden Quellengattungen nicht grundlegend widersprechen, liegt nahe, eher die zweite Möglichkeit in Betracht zu ziehen.

Ein wichtiger Unterschied zwischen den epigraphischen Darstellungen und der bei Hemādri ist, dass letztere keine einzige Königin nennt. ${ }^{69}$ Dies ist ein Indiz dafür, dass sich bezüglich ihrer Funktion Genealogien in Inschriften von denen in anderen Textgattungen unterschieden. Während Hemādri bestrebt gewesen zu sein scheint, die Mitglieder der Familie, der er diente, möglichst vollständig aufzulisten, wiesen die Yādavas ihre Urkundenverfasser offenbar an, eine dynastiepolitisch bewusste Auswahl zu treffen und auch von Heiraten zu berichten.

Unter den Śilāhāras und Yādavas kam es zu starken Verschiebungen in den Vassalitäts- und Subvasallitätsstrukturen. Regional- und Gebietsfürsten gaben in steigendem Maße selbständig Urkunden heraus, in denen sie meist deutliche Loyalitätsbekundungen ablegten und für die sie nach dem Vorbild ihrer Oberherren eigene Genealogien und Titulaturen formulieren ließen. Vasallenfürsten und lokale Eliten initiierten den im 10. Jahrhundert einsetzenden Aufschwung des hinduistischen Tempelwesens in Maharashtra, mit dem eine zunehmende inschriftliche Verwendung der Regionalidiome einherging. ${ }^{70}$ Nur zum Teil wurden derartige Aktivitäten zugunsten lokaler Tempel auf Kupfertafeln und in Sanskrit dokumentiert; sehr viel häufiger hielt man solche Berichte und Verfügungen auf Stein und in einem Mischidiom aus Sanskrit und Alt-Marāțhī oder Alt-Kannada fest. Die Anzahl der belegten Verleihungen an Tempel im Verhältnis zu denen an Brahmanen (ohne einen erkennbaren Tempelbezug) wuchs seit dem 11. Jahrhundert beträchtlich an. Unter den Śilāhāras und Yādavas galt das Tempelpatronat vor allem sivaitischen Schreinen, aber auch einigen Heiligtümern für Göttinnen und für den Sonnengott. Bereits bei Bhillama II., dem ersten historisch verbürgten Yādava-Herrscher, fällt eine besondere Nähe zwischen dem Königtum und Śiva, ${ }^{71}$ eine Art śivaitischer Herrschaftslegitimation, auf. Die einzige von ihm überlieferte Inschrift, die aus dem Śaka-Jahr 922 (1000 n. Chr.) datiert, beginnt mit einer Anrufung an und einer Strophe für Siva und stellt danach eine direkte Beziehung zwischen dem Gott und Bhillama II. her. ${ }^{72} \mathrm{Zu}$ nehmend wurden auch Śaiva-Asketen gefördert, die im frühmittelalterlichen Königsritual eine starke Konkurrenz für parallele Ansprüche brahmanischer

69 Ebd., 336f.

70 Ebd., 445.

71 Ebd., 421.

72 Franz Kielhorn, Samgamner Copper-Plate Inscription of the Yadava Bhillama II. The Śaka year 922, in: Epigraphia Indica 2 (1894), 212-221. 
Hofpriester darstellten. ${ }^{73}$ All diese Veränderungen waren das Ergebnis vielfältiger Interaktionen im Spannungsfeld zwischen Herrschern und regionalen Eliten.

\section{Literaturverzeichnis}

Heinz Bechert, Zum Ursprung der Geschichtsschreibung im indischen Kulturbereich (Nachrichten der Akademie der Wissenschaften in Göttingen, Philologisch-Historische Klasse, 1969, 2), Göttingen 1969.

Devadatta R. Bhandarkar, Cambay Plates of Govinda IV.; Saka-Samvat 852, in: Epigraphia Indica 7 (1902/03), 26-47.

Devadatta R. BHANDARKAR, Dhulia Plates of Karkaraja; Saka-Samvat 701, in: Epigraphia Indica 8 (1905/06), 182-187.

Ramakrishna G. Bhandarkar, Appendix C, in: Ders., Early History of the Deccan and Miscellaneous Historical Essays (Reprint of Collected Works 3), Pune 1983.

Duncan M. Derrett, Bhūbharana, bhūpālana, bhübhojana. An Indian Conundrum, in: Bulletin of the School of Oriental and African Studies 22/1 (1959), 108-123.

Moreshwar G. Dikshiт, Prince of Wales Museum Plates of Govindaraja: Saka 732, in: Epigraphia Indica 26 (1941/42), 248-255.

Cédric Ferrier/Judit TörzsöK, Meditating on the King's Feet? Some Remarks on the Expression pādānudhyāta, in: Indo-Iranian Journal 51 (2008), 93-113.

John Faithful FleEt, Nilgund Inscription of the Time of Amoghavarsha I.; A. D. 866, in: Epigraphia Indica 6 (1900/01), 98-108.

John Faithful FleEt, Some Records of the Rashtrakuta Kings of Malkhed. The appellations of the Rāshṭrakūtas of Mālkheḍ, in: Epigraphia Indica 6 (1900/01), 167-198.

Ryosuke FURUI, Indian Museum Copper Plate Inscription of Dharmapala, Year 26. Tentative Reading and Study, in: South Asian Studies 27/2 (2011), 145-156.

P. L. GuptA, Nesarika Grant of Govinda III, Saka 727, in: Epigraphia Indica 34 (1961/62), 123-134.

David Henige, Some Phantom Dynasties of Early and Medieval India. Epigraphic Evidence and the Abhorrence of a Vacuum, in: Bulletin of the School of Oriental and African Studies 38 (1975), 525-549.

Franz Kielhorn, Samgamner Copper-Plate Inscription of the Yadava Bhillama II. The Śaka year 922, in: Epigraphia Indica 2 (1894), 212-221.

Hermann KULKE, Geschichtsschreibung und Geschichtsbild im hinduistischen Mittelalter, in: Saeculum 30 (1979), 100-112.

Hermann KulKe, Some Observations on the Political Functions of Copper-Plate Grants in Early Medieval India, in: Bernhard Kölver (ed.), Recht, Staat und Verwaltung im klassischen Indien, München 1997, 237-243.

Vasudev Vishnu Mirashi, Inscriptions of the Kalachuri-Chedi Era (Corpus Inscriptionum Indicarum 4), Ootacamund 1955.

73 Vgl. hierzu die ausführliche Studie von Alexis SANDERson, Religion and the State. Śaiva Officiants in the Territory of the King's Brahmanical Chaplain, in: Indo-Iranian Journal 47 (2004), 229-300. 
Vasudev Vishnu Mirashi/L. R. Kulkarni, Anjanavati Plates of Govinda III: Saka Year 722, in: Epigraphia Indica 23 (1935/36), 8-18.

Alexis Sanderson, Religion and the State. Śaiva Officiants in the Territory of the King's Brahmanical Chaplain, in: Indo-Iranian Journal 47 (2004), 229-300.

Annette Schmiedchen, Religious Patronage and Political Power. The Ambivalent Character of Royal Donations in Sanskrit Epigraphy, in: Journal of Ancient Indian History 27 (2010/11), 154-166.

Annette Schmiedchen, Herrschergenealogie und religiöses Patronat. Die Inschriftenkultur der Rāṣtrakūṭas, Śilāhāras und Yādavas (8. bis 13. Jahrhundert) (Gonda Indological Series 17), Leiden 2014a.

Annette Schmiedchen, Art. 3. Typologisierungen. 3.6. Indien, in: Michael Borgolte (ed.), Enzyklopädie des Stiftungswesens in mittelalterlichen Gesellschaften, Bd. 1: Grundlagen, Berlin 2014b, 229-248.

Annette Schmiedchen, Brahmanische Wanderungsbewegungen im mittelalterlichen Indien. Gewinner und Verlierer, in: Zeitschrift für Geschichtswissenschaft 63/3 (2015), 227-236.

Annette Schmiedchen, Art. 7. Religiöses Verdienst und weltliche Ambitionen. 7.6. Indien, in: Michael Borgolte (ed.), Enzyklopädie des Stiftungswesens in mittelalterlichen Gesellschaften, Bd. 2: Das soziale System Stiftung, Berlin 2016, 72-85.

Dinesh Chandra SirCAR, Indian Epigraphical Glossary, Delhi 1966.

Walter Slaje, Kaschmir im Mittelalter und die Quellen der Geschichtswissenschaft, in: Indo-Iranian Journal 48 (2005), 1-70.

Vishnu Sitaram Sukthankar, Bhandak Plates of Krishnaraja I.: Saka 694, in: Epigraphia Indica 14 (1917/18), 121-129.

H. S. Thosar/A. A. Hingmire, Barsi Plates of Krishna I, in: Journal of the Epigraphical Society of India 11 (1984), 106-113.

Fred VIRKus, Die Könige und das Kaliyuga - Bezugnahmen auf die Weltzeitaltertheorie in frühmittelalterlichen Inschriften, in: Beiträge des Südasieninstituts (Humboldt-Universität zu Berlin) 9 (1997), 37-43.

Michael Witzel, Das Alte Indien (Beck'sche Reihe Wissen 2304), München 2003. 
(c) 2019, VधR unipress GmbH, Göttingen 